\title{
The assesement of bioactive potential and sensory acceptability of coffee and its byproducts- cascara and silverskin
}

\author{
Ana Mandura Jarić ${ }^{1}$, Marion Natucci Pasquino ${ }^{2}$, Evan Cazalens $^{2}$, Danijela Šeremet ${ }^{1}$, Robert Pudić ${ }^{3}$, Aleksandra Vojvodić \\ Cebin ${ }^{1}$,Draženka Komes ${ }^{1 *}$
}

\begin{abstract}
${ }^{1}$ Faculty of Food Technology and Biotechnology, University of Zagreb, Pierottijeva 6, 10000 Zagreb, Croatia
${ }^{2}$ AgroSup Dijon, Université Bourgogne Franche-Comté, Dijon, 26 Boulevard Dr Petitjean, France

${ }^{3}$ Quahwa Coffee Roastery \& Coffee shop, Ulica Nikole Tesle 9/1, Zagreb, Croatia
\end{abstract}

*Corresponding author: dkomes@pbf.hr

\begin{abstract}
Through the decades, coffee has been representing one of the most consumed beverages worldwide. During the coffee cherry processing, significant amount of coffee byproducts is generating, thus ending as an agro-industrial waste. Besides macro-and micronutrient content, coffee cascara and coffee silverskin are coffee byproducts which can have valuable bioactive potential. For that purpose, ethanol extracts and water infusions (beverages) of green coffee, roasted coffee, coffee cascara and coffee silverskin were analysed for total phenolic content, antioxidant capacity and individual identification of polyphenolic compounds by High Performance Liquid Chromatography Analysis paired with PhotoDiode Array detector (HPLC-PDA), with further sensory analysis of beverages. Results showed that beverages were generally evaluated with the higher bioactive potential than ethanol extracts, while roasted coffee beverages exhibited the highest content of TPC and antioxidant capacity in comparison to the ethanol extract. Among all samples, green coffee beverage was evaluated as the most valuable source of 5-O-caffeoylquinic acid $(36.7 \mathrm{mg} / \mathrm{g} \mathrm{dw})$, while coffee cascara $(9.2 \mathrm{mg} / \mathrm{g} \mathrm{dw})$ contained the highest content of caffeine. Although roasted beverage expectedly scored as the highest acceptable (6.2), silverskin and cascara were evaluated with relatively satisfactory results of the overall acceptability (4.6-5.2), thus showing the potential for the improvement in terms of preparation and, furthermore, greater consumer acceptance.
\end{abstract}

\section{Keywords: coffee, coffee byproducts, bioactive compounds, beverages, sensory analysis}

\section{Introduction}

Coffee represents one of the most favorable beverages worldwide arising from complex and distinctive taste and well- known stimulative effects (Gloess et al., 2013). It is internationally traded as coffee beans and is valued as the second most important commodity after oil. (Esquivel and Jiménez, 2012). Containing more than 1000 bioactive compounds, regular coffee intake (3-4 cups daily) can contribute to the prevention of specific health diseases, including cardiovascular diseases, metabolic and neurological conditions (British Coffee Association, 2016; Poole et al., 2017). The coffee tree or shrub is a flowering plant, belonging to Rubiaceae family and containing more than 100 widely known coffee species, among which Coffea arabica L. and Coffea canephora P.(commonly known as "Arabica" and "Robusta", respectively) are the most important economically (Davis et al., 2006). Strong and dynamic culture of coffee consumption is continuing to empower its economic importance, with expectations of Compound annual growth rate (CAGR) by $8.28 \%$ until 2025 (Statista, 2021).

Behind each cup of coffee, there is a complex and delicate process of processing and preparation. Coffee processing can be done in two distinct ways, namely dry or wet procedure. The former comprises of drying the coffee fruit and further mechanical removal of cascara, i.e. the dried fleshy part of the cherry consisting of pericarp (husk), mesocarp (pulp) and endocarp (parchment). This procedure is commonly used for Robusta beans (Mussatto et al., 2011). In wet processing, the distinctive step includes dehulling and depulping of fresh cherries, followed by fermentation of the green seeds covered with mucilage- pectin layer as the part of the pulp (Alves et al., 2011; Ferrão, 2009). This procedure is mostly conducted for Arabica coffee and it provides higher quality of the beans in terms of bioactive content and sensory profile. Further steps in both processing type include removal of the remained endocarp (parchment) and roasting of green coffee upon which the outer layer of the coffee bean- epiderma (silverskin) separates from the bean and is being removed as a byproduct (Cubero-Castillo et al., 2017). In accordance to the massive coffee production, a noticeable amount of byproducts, such as cascara, parchment and silverskin are being generated. Cascara comprise up to $45 \%$ of the coffee cherry (Del Castillo et al., 2019; Esquivel and Jiménez, 2012) while silverskin accounts for approximately 1\% ( Alves et al., 2017). Annually, this would represent at least 25 million tons in total of the mentioned waste, which are mostly inadequately disposed due to the lack of profitable uses (Pua et al., 2021) and as such pose an environmental hazard (Ateş and Elmacı, 2018). Within the concept of sustainable coffee production, alternative uses of coffee processing byproducts are increasingly being investigated. Except of rich macro- and micronutrients content which may, furthermore, find potential application in different industrial sectors, such as biorefinery (Hudeckova et al., 2018), agroindustry (Murthy and Naidu, 2012), pharmaceutical (Yoo et al., 2018), cosmetic industry (Riberio et al., 2018), food industry (Bertolino et al., 2019; Ateş and Elmac1, 2018), these byproducts also represent potential valuable source of bioactive compounds. Among them, hydroxycinnamic acides, i.e. chlorogenic acid derivatives and methylxanthines, i.e. caffeine, are the most represented. Its positive effect on human health, as well as, stimulative related effects are well known (Das Neves et al., 2019). Valorization of cascara and silverskin in terms of extraction of bioactive compounds and its further implementation into various functional food products may have a noticeable potential on the market given the growing interest of consumers for polyphenol-rich "super foods" (Statista, 2020).

In order to explore the bioactive potential of selected coffee byproductscascara and silverskin, along with green coffee and roasted coffee, ethanol extracts and beverages were analysed for TPC and antioxidant capacity, with further quantification of present bioactive compounds by HPLC. Furthermore, sensory analysis was also conducted for the estimation of general consumer acceptability of prepared beverages. Such obtained results will be useful indicators for the possibility of valorizing them as potential commercialize food products. 


\section{Materials and methods}

\section{Materials and chemicals}

Coffee silverskin, roasted and green coffee beans (Coffea arabica) were obtained from Brasil (region Coletivo) while coffee cascara (Coffea arabica, var. typica) was provided from Dominican Republic (region Barahona)

(S)-6-Methoxy-2,5,7,8-tetramethylchromane-2-carboxylic acid (Trolox), 2,2-Diphenyl-1-picrylhydrazyl (DPPH), 2,20-Azino-bis(3 ethylbenzothiazoline-6-sulfonic acid) diammonium salt (ABTS), gallic acid $(>97 \%)$, caffeine $(>99 \%)$, 3-4 dihydroxybenzoic acid $(>98 \%)$, theobromine $(>99 \%), \quad 5-O$-caffeoylquinic acid $(>98 \%), 4-O-$ caffeoylquinic acid (98\%), 3-O-caffeoylquinic acid (>99\%) and epicatechine galate (>99\%) were purchased from Sigma-Aldrich (St. Louis, USA). Folin-Ciocalteau reagent and sodium carbonate were purchased from Kemika d.o.o., Zagreb. Methanol was supplied from Panreac (Barcelona, Spain), while ethanol, formic acid and acetonitrile were purchased from Carlo Erba (Val de Reuil, France). All chemicals used for experimental procedures were of analytical or HPLC grade.

\section{Preparation of samples}

All samples were firstly milled in electric grinder and then sieved in a stainless-steel sieve $(450 \mu \mathrm{m})$. Solely the fraction less than $450 \mu \mathrm{m}$ were used for further analysis.

\section{Extraction of bioactive compounds}

All four samples were double extracted with $70 \%$ ethanol (v/v) using $1 \mathrm{~g}: 20 \mathrm{~mL}$ solid-to-solvent ratio.

Extraction was performed on $80^{\circ} \mathrm{C}$ for 20 minutes using reflux condenser with constant stirring (SMHS-6, Witeg Labortechnik GmbH). After cooling down at room temperature, obtained beverages were centrifuged at a speed of $10000 \mathrm{rpm}$ for 10 minutes (SL-8R centrifuge, ThermoScientific) and at a temperature of $5^{\circ} \mathrm{C}$, and supernatants were collected. Solid residues undergone second extraction using the same parameters as previously. At the end, filtrates for each sample were combined and filtered under the vacuum using Büchner funnel. All analyses were performed in triplicate $(n=3)$.

\section{Preparation of beverages}

$2 \mathrm{~g}$ of grounded cascara and silverskin samples with roasted and green coffee beans were infused in $100 \mathrm{~mL}$ of distilled water $\left(95^{\circ} \mathrm{C}\right)$ during 10 minutes with periodically mixing. Such prepared beverages were sensory evaluated and bioactive composition was characterized using spectrophotometric and HPLC methodology.

\section{Physico-chemical analysis}

\section{Determination of dry matter}

The dry matter $(\mathrm{dw})$ content is determined according to the modified AOAC method (AOAC 930.15, 1990). $0.5 \mathrm{~g}$ (to within \pm 0.0001 ) of grounded and well-homogenized green and roasted coffee beans, as well as, cascara and silverskin samples were weighed and placed in a cooled and previously weighed aluminum cup with a lid. The uncovered sample cup and cover are dried in an oven at $105^{\circ} \mathrm{C}$ for 2 hours. After the drying time has elapsed, the aluminum cup is covered with the lid and weighed as soon as it has cooled to room temperature. The procedure is repeated until a constant mass of the sample is reached (with an accuracy of \pm $0.0003 \mathrm{~g})$. All analyses were performed in triplicate $(n=3)$.

\section{Determination of bioactive potential}

\section{Determination of total phenolic content (TPC)}

The TPC was determined according to the method by Singleton and Rossi (1965). $3.95 \mathrm{~mL}$ of distilled water, $50 \mu \mathrm{L}$ of diluted extract, 250 $\mu \mathrm{L}$ of Folin-Ciocalteu reagent and $750 \mu \mathrm{L}$ of sodium carbonate were mixed in a test tube. The samples were left to stand for 2 hours at room temperature, after which the absorbance of the developed blue color was measured at $765 \mathrm{~nm}$, relative to blank sample. The results were expressed in mg gallic acid equivalents (GAE) per gram of dry weight of sample (mg GAE/g dw). All analyses were performed in triplicate $(n=3)$.

\section{Determination of antioxidant capacity by ABTS and DPPH assays}

To determine the antioxidant capacity by ABTS method, the sample (20 $\mu \mathrm{L}$ ) was homogenized with $2 \mathrm{~mL}$ of ABTS. After $6 \mathrm{~min}$, the absorbance of $734 \mathrm{~nm}$ was determined (Genesys 10S, ThermoScientific). The results were calculated as mg Trolox equivalents per gram of sample dry weight (mmol TroloxE/g dw) by using the Trolox standard calibration curve (Re et al., 1999).

The second method for determining antioxidant capacity included measurement of DPPH radical scavenging activity in the presence of antioxidants in the samples, by mixing the $100 \mu \mathrm{L}$ of the sample with 3.9 $\mathrm{mL}$ of DPPH solution in a test tube. After the reaction, the absorbance was determined at $515 \mathrm{~nm}$. The DPPH radical scavenging activity was expressed as mg of Trolox equivalents per gram of dry weight (mmol TroloxE/g dw) (Brand-Williams et al., 1995). All analyses were performed in triplicate $(n=3)$.

\section{High Performance Liquid Chromatography (HPLC) analysis of phenolic compounds and methylxanthines}

The HPLC analysis of ethanol extracts and beverages was employed on an Agilent Series 1200 chromatographic system (Agilent Technologies, Santa Clara, CA, USA) coupled with a Photo-Diode Array detector (PAD) (Agilent Technologies, Santa Clara, CA, USA) and using a Zorbax Extend C18 $(4.6 \times 250 \mathrm{~mm}, 5 \mu \mathrm{m}$ i.d.) chromatographic column (Agilent Technologies, USA). Firstly, all samples were filtered through a $0.20 \mu \mathrm{m}$ membrane filter (regenerated cellulose filter, Supelco, Bellefonte, PA, USA) prior to the analysis. Gradient elution included two-component mobile phase consisting of (A) $1 \%(\mathrm{v} / \mathrm{v})$ formic acid solution in water and (B) $1 \%(\mathrm{v} / \mathrm{v})$ formic acid solution in acetonitrile, according to the following order: $0 \mathrm{~min}-93 \% \mathrm{~A}, 7 \% \mathrm{~B} ; 5 \mathrm{~min}-93 \% \mathrm{~A}, 7 \% \mathrm{~B} ; 45 \mathrm{~min}$ $-60 \%$ A, $40 \%$ B; $47 \min -30 \%$ A, $70 \% ; 52 \min -30 \%$ A, $70 \%$ B. The flow was $1 \mathrm{~mL} / \mathrm{min}$, the injection volume $5 \mu \mathrm{L}$ and the column temperature $25^{\circ} \mathrm{C}$. The chromatograms were recorded at $260,278,320$ and $350 \mathrm{~nm}$. Identification and quantification of phenolic compounds and methylxanthines was conducted by comparing the retention times with commercially available standards and using calibration curves for each identified compund $(20-100 \mu \mathrm{g} / \mathrm{mL})$. The analysis was performed in a triplicate $(n=3)$.

\section{Sensory analysis}

Sensory properties of cascara, silverskin, green and roasted coffee beverages were analysed by quantitative descriptive analysis method and corresponding literature (Martinez-Saez et al., 2014). The sensory evaluation was carried out in one session involving 10 untrained panelists, but with the previous experience in descriptive sensory analysis. All prepared beverages were graded for: color, aroma, taste, aftertaste and their overall acceptability and for each sensory attribute. 9-point hedonistic scale with scoring 1 (the lowest acceptable) - 9 (the highest acceptable) was employed. The average point number was calculated for each of the attributes. 


\section{Statistical analysis}

Statistical analysis of all samples was performed with one-way ANOVA analysis of variance with post-hoc analysis using Tukey test at significance level of $\mathrm{p}<0.05$ in SPSS Statistics Software 17.0. (IBM).

\section{Results and discussion}

\section{Bioactive potential determination of analysed samples}

In order to quantitatively assess the total bioactive content of analysed ethanol extracts and prepared beverages, TPC and antioxidant capacity were determined. According to the Figure 1., TPC values were significantly higher $(p<0.05)$ for green and roasted coffee beverages (49.65 mg GAE/g dw- $48.09 \mathrm{mg}$ GAE/g dw) in compare to ethanol extracts (34.65 mg GAE/g dw- $31.02 \mathrm{mg} \mathrm{GAE} / \mathrm{g} \mathrm{dw}$ ), except of cascara and silverskin sample. It has been reported that extractability of compounds depends on many factors, such as powder/solvent ratio, temperature and time of extraction, coffee grinding degree, as well as, coffee variety type and roasting conditions (Alves et al., 2007; Alves et al., 2010).

As expected, green coffee (49.56 mg GAE/g dw) and roasted coffee (48.09 $\mathrm{mg} \mathrm{GAE} / \mathrm{g} \mathrm{dw}$ ) beverages were richer in TPC than evaluated by products- coffee cascara (19.53 $\mathrm{mg} \mathrm{GAE} / \mathrm{g} \mathrm{dw}$ ) and silverskin (10.62 mg $\mathrm{GAE} / \mathrm{g} \mathrm{dw}$ ). Similar results for cascara were also obtained in Nguyen Phuong et al. (2019) while measured value for TPC in silverskin was lower than that reported by Mesías et al. (2014) and Iriondo- DeHond et al. (2019). Such differences are notably influenced by different factors, such as variety of coffee, fermentation process, applied extraction method, extraction conditions etc.

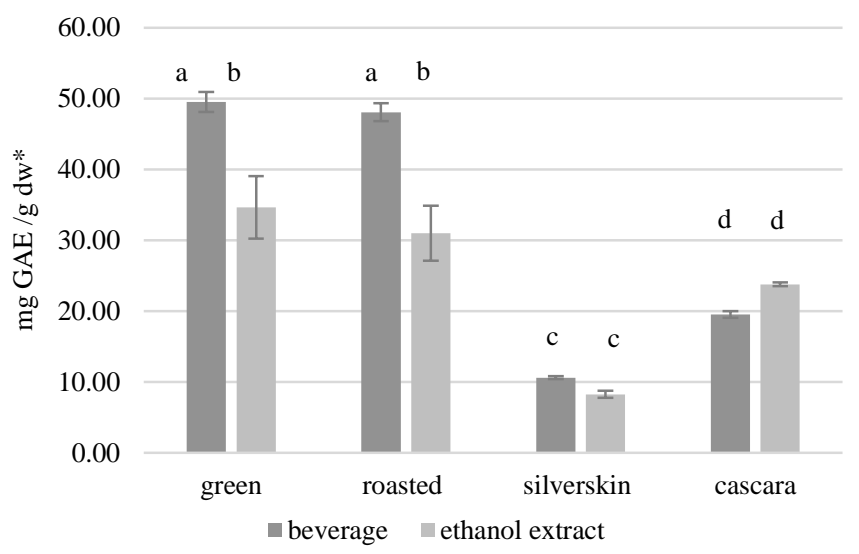

*Results are expressed on mg GAE/g of dry weight. Samples marked with the same letters denote non- significant differences between the means $(\mathrm{p}<0.05)$

Figure 1. Results of total phenolic content for analysed samples.

Antioxidant capacity measured by ABTS and DDPH assays was also estimated (Figure 2. and 3.) and high correlation with TPC were also established (TPC:ABTS $=0.92$, TPC:DPPH= 0.93). As expected, green and roasted coffee samples generally followed the trend of TPC values in terms of the highest antioxidant capacity for beverages, exhibiting the value range for ABTS between 0.202- $0.311 \mathrm{mmol}$ TroloxE/g dw, and 0.208- 0.220 mmol TroloxE/g dw for DPPH assay. Additionally, higher value of ABTS for roasted coffee may be ascribed to the fact that ABTS radical cation tend to react with broader range of compounds (Mareček et al., 2017). Among ethanol extracts, green and roasted extracts were characterized with higher antioxidant capacity than analysed byproducts, due to the significant content of chlorogenic acid derivatives and alkaloids in green beans, as well as, melanoidins, which are formed through the complex Maillard reactions during roasting process (Ballesteros et al., 2014).

Regarding byproducts, cascara ethanol extract showed to be the byproduct with a higher antioxidant capacity (ABTS: $0.141 \mathrm{mmol}$ TroloxE/g dw; DDPH: $0.111 \mathrm{mmol}$ TroloxE/g dw), in compare to the lower values of antioxidant capacity determined in silverskin (ABTS: $0.069 \mathrm{mmol}$ TroloxE/g dw; DDPH: $0.041 \mathrm{mmol}$ TroloxE/g dw). Furthermore, Ateş and Elmac1 (2018) reported similar results for water extract silverskin in the amount of $0.019 \mathrm{mmol}$ TroloxE/g dw, determined by DPPH assay.

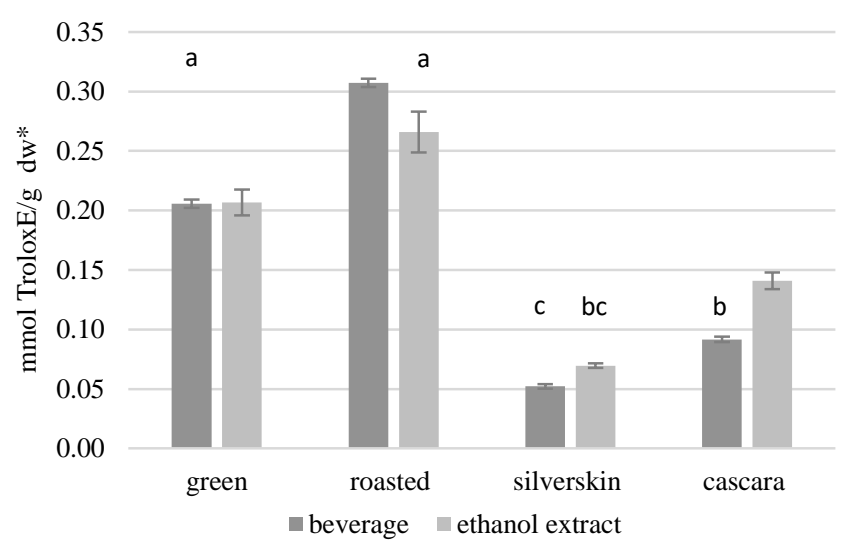

*Results are expressed on mg TroloxE/g of dry weight. Samples marked with the same letters denote non- significant differences between the means $(\mathrm{p}<0.05)$.

Figure 2. Antioxidant capacity of analysed samples determined by ABTS assay.

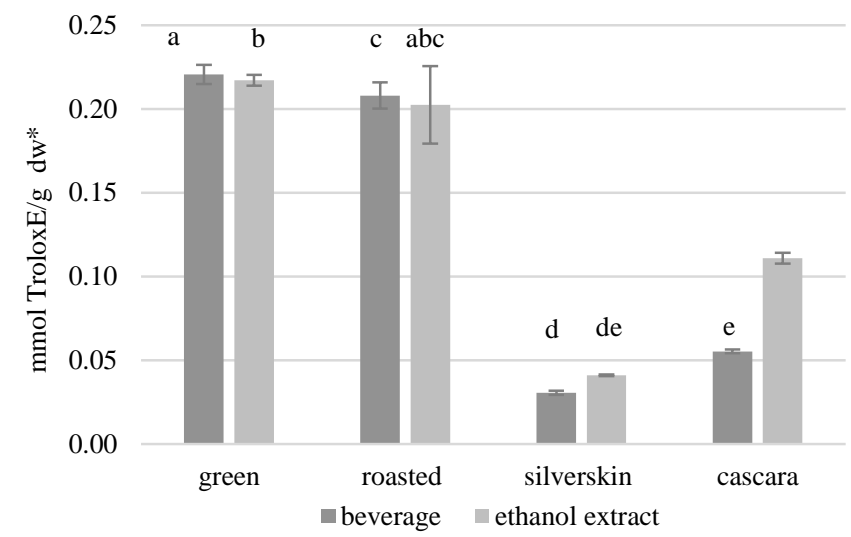

*Results are expressed on mg TroloxE/g of dry weight. Samples marked with the same letters denote non- significant differences between the means $(\mathrm{p}<0.05)$.

Figure 3. Antioxidant capacity of analysed samples determined by DDPH assay.

\section{HPLC analysis of phenolic compounds and methylxanthines}

Beside of determination of bioactive potential by spectrophotometric methods, individual quantification of bioactive compounds- polyphenols and methylxanthines was conducted by HPLC- PDA analysis (Table 1.). Regarding green coffee, similar results for ethanol extract and beverage were observed. Slightly smaller content of caffeine $(1.9 \mathrm{mg} / \mathrm{g} \mathrm{dw})$ was analysed in ethanol extract in comparison to the prepared beverage $(2.2$ $\mathrm{mg} / \mathrm{g} \mathrm{dw}$ ), as well as, the content of chlorogenic acid derivatives, with 5 -O-caffeoylquinic acid $(33.7 \mathrm{mg} / \mathrm{g} \mathrm{dw})$ (Table 1.) as the most dominant phenolic compound (Budryn et al., 2013). Notable variations in the caffeine and quantitative profile of phenolic acids are influenced by many conditions, e.g. geographical location, climate conditions, growth conditions, humidity during the storage etc. (Farah et al., 2006). In ethanol extract of roasted coffee, theobromine $(0.3 \mathrm{mg} / \mathrm{g} \mathrm{dw})$, caffeine (2.2 mg/g dw), 3-O-caffeoylquinic acid $(2.2 \mathrm{mg} / \mathrm{g} \mathrm{dw}), 4-O$ caffeoylquinic acid $(4.2 \mathrm{mg} / \mathrm{g} \mathrm{dw})$ and 5 - $O$-caffeoylquinic acid $(8.1$ $\mathrm{mg} / \mathrm{g} \mathrm{dw}$ ) were detected. Similar results were obtained for prepared roasted coffee beverage, resulting in $5-O$-caffeoylquinic acid $(8.1 \mathrm{mg} / \mathrm{g}$ dw) in the highest content (Król et al., 2020). 
Table 1. Composition of polyphenols and methylxanthines in analysed samples

\begin{tabular}{|c|c|c|c|c|c|c|c|}
\hline & $\begin{array}{l}\text { 3-4-DHB- } \\
\text { acid (mg/g } \\
\left.\mathrm{dw}^{*}\right)\end{array}$ & $\begin{array}{l}\text { theobromine } \\
(\mathrm{mg} / \mathrm{g} \mathrm{dw})\end{array}$ & $\begin{array}{l}\text { caffeine } \\
(\mathrm{mg} / \mathrm{g} \mathrm{dw})\end{array}$ & $\begin{array}{l}\text { ECG } \\
(\mathrm{mg} / \mathrm{g} \mathrm{dw})\end{array}$ & $\begin{array}{l}\text { 3-O-caffeoylquinic } \\
\text { acid }(\mathrm{mg} / \mathrm{g} \mathrm{dw})\end{array}$ & $\begin{array}{l}\text { 5-O-caffeoylquinic } \\
\operatorname{acid}(\mathrm{mg} / \mathrm{g} \mathrm{dw})\end{array}$ & $\begin{array}{l}\text { 4- } O \text {-caffeoylquinic } \\
\text { acid (mg/g dw) }\end{array}$ \\
\hline & \multicolumn{7}{|c|}{ ethanol extracts $(70 \% . \mathrm{v} / \mathrm{v})$} \\
\hline silverskin & n.d. & $0.5 \pm 0.0$ & $5.2 \pm 0.1^{\mathrm{a}}$ & $0.6 \pm 0.0$ & n.d & $0.3 \pm 0.0^{\mathrm{a}}$ & n.d \\
\hline cascara & $1.1 \pm 0.0$ & $0.3 \pm 0.0$ & $8.8 \pm 0.2^{b}$ & n.d & n.d & $1.4 \pm 0.0^{\mathrm{b}}$ & n.d \\
\hline green & n.d. & n.d. & $1.9 \pm 0.2^{\mathrm{c}}$ & n.d & $1.9 \pm 0.2$ & $33.7 \pm 3.3^{\mathrm{c}}$ & $4.1 \pm 0.4^{\mathrm{a}}$ \\
\hline \multirow[t]{2}{*}{ roasted } & n.d. & n.d. & $2.2 \pm 0.1^{\mathrm{d}}$ & n.d & $2.2 \pm 0.1$ & $8.1 \pm 0.4^{\mathrm{d}}$ & $4.2 \pm 0.2^{\mathrm{a}}$ \\
\hline & \multicolumn{7}{|c|}{ beverages } \\
\hline silverskin & $0.1 \pm 0.0$ & $0.6 \pm 0.0$ & $5.3 \pm 0.2^{\mathrm{a}}$ & $0.8 \pm 0.0$ & n.d & $0.4 \pm 0.0^{\mathrm{ab}}$ & n.d \\
\hline cascara & $1.2 \pm 0.0$ & $0.2 \pm 0.0$ & $9.2 \pm 0.5^{b}$ & n.d & n.d & $1.5 \pm 0.0^{\mathrm{ab}}$ & n.d \\
\hline green & n.d. & n.d. & $2.2 \pm 0.1^{\mathrm{cd}}$ & n.d & $2.7 \pm 0.1^{\mathrm{a}}$ & $36.7 \pm 1.3^{\mathrm{c}}$ & $4.9 \pm 0.1$ \\
\hline roasted & n.d. & n.d. & $2.3 \pm 0.0^{\mathrm{d}}$ & n.d & $2.9 \pm 0.1^{\mathrm{a}}$ & $8.7 \pm 0.0^{\mathrm{d}}$ & $4.6 \pm 0.0$ \\
\hline
\end{tabular}

*mg/g dw= expressed as mg/g of dry weight

n.d. $=$ not detected

Results are expressed as the mean value \pm standard deviation. Samples marked with the same letters in each column denote non- significant differences between the means $(\mathrm{p}<0.05)$.

Lower content of caffeine and chlorogenic acid derivatives in roasted coffee can be ascribed to many factors, such as humidity of the green coffee beans, applied roasting temperature, roasting time and low velocity of roasting air etc., which notably affect on decrease of its final content due to the decomposition caused by non- enzymatic reaction, thus forming Maillard-reaction compounds (Summa et al., 2007; Budryn et al., 2013).

Concerning coffee byproducts, beverages also exhibited slightly higher values of extracted bioactive compounds than ethanol extracts which is in the agreement with TPC results. The distinct content in certain polyphenols between beverages and ethanol extracts in all analysed samples may be explained by the use of a different solvent. Indeed, Huaman- Castilla et al. (2019) demonstrated that 5-O-caffeoylquinic acid content decreases when the content of ethanol increases.

Cascara beverage showed to be richer in the caffeine content $(9.2 \mathrm{mg} / \mathrm{g}$ $\mathrm{dw})$ than silverskin $(5.3 \mathrm{mg} / \mathrm{g} \mathrm{dw})$, while the content of $5-O$ caffeoylquinic acid $(\mathrm{mg} / \mathrm{g} \mathrm{dw})$ was greatly lower in cascara $(1.5 \mathrm{mg} / \mathrm{g}$ $\mathrm{dw})$ and silverskin $(0.4 \mathrm{mg} / \mathrm{g} \mathrm{dw})$ compare to the previously mentioned green or roasted coffee beverage. Similar results were reported by Heeger et al. (2017). Moreover, in coffee pulp which is part of cascara, three major phenolic compounds have been quantified, such as 5-O-caffeoylquinic acid, caffeine and theobromine (Manasa, 2021), which is in accordance to this study. However, the presence of 3-O-caffeoylquinic acid and 4-O-caffeoylquinic acid was not detected, neither in cascara or silverskin.

The content of analysed bioactive compounds in silverskin highly depends, among other factors, on the variety of coffee. Mesías et al. (2014) found that caffeine content was significantly higher in Robusta than in Arabica silverskin coffee. Furthermore, Martinez-Saez et al. (2014) stated that the presence of 5-O-caffeoylquinic acid would amount to $3-4 \%$ of the total antioxidant capacity of such byproducts but decrease trend occurs as the result of specific parameters during the roasting process. It seems of great importance to take this factor into consideration when selecting the different roasting parameters in order to prevent any large loss in 5-O-caffeoylquinic acid in the final product.

\section{Sensory analysis}

In order to estimate consumer acceptability of prepared coffee and coffee byproducts beverages, sensory analysis was performed (Figure 4.). All four analysed samples, i.e. green coffee, roasted coffee, cascara and silverskin demonstrated variable profile in terms of evaluated sensory characteristics (Figure 4.).

Colour for roasted coffee was evaluated with the highest score (7), while green coffee seemed to be at least acceptable (1.6) due to its unattractive, pale yellow color. In terms of aroma, all four samples were sensory marked as follows: roasted coffee (7) > silverskin (5.2) > green coffee (4.3) > cascara (2.8). After roasted coffee (7), cascara was estimated with the most favourable taste (6.33) of all samples. Regarding aftertaste, itis hardly discernible for all samples, with roasted beverage being the product with the most dominant aftertaste (3.3).

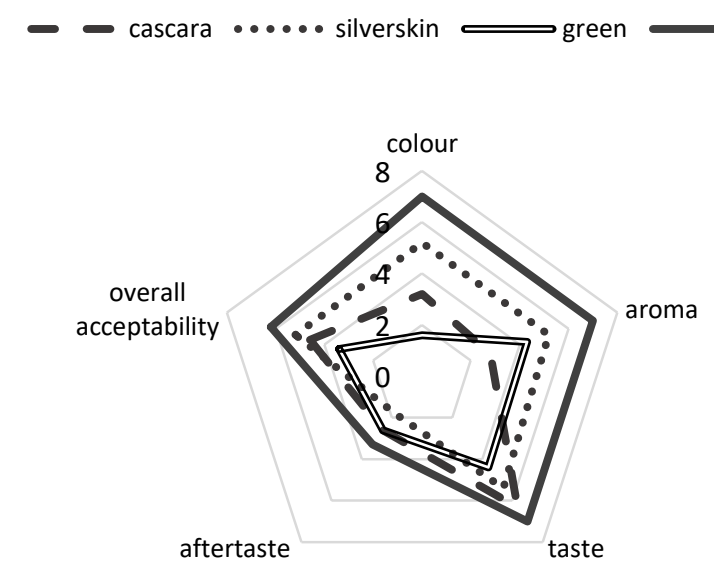

Figure 4. Spider chart representing the results of sensory attributes regarding cascara, silverskin, green coffee and roasted coffee beverage. 
Table 2. Profile of sensory attributes- aroma and taste for prepared beverages

\begin{tabular}{|l|l|l|}
\hline beverage & aroma & taste \\
\hline silverskin & $\begin{array}{l}\text { roasted nuts, citrus, green tea, earthy, dried } \\
\text { hay, fruity, honey, barley, forage }\end{array}$ & $\begin{array}{l}\text { herbal, nuts, bitter, sour, caramel, hazelnut, } \\
\text { fruity, tasty, coffee, sweet, unpleasant, cereals }\end{array}$ \\
\hline cascara & $\begin{array}{l}\text { roasted, ash, sweet, strong, fruity, rose hip, } \\
\text { citrus, coffee, honey, acacia }\end{array}$ & $\begin{array}{l}\text { nuts, bitter, sour, astringent, sweet, rose hip, } \\
\text { fruity, sweet, tasty, full flavour }\end{array}$ \\
\hline green & $\begin{array}{l}\text { earthy, grassy, herbal, strong, woody, dried } \\
\text { hay }\end{array}$ & $\begin{array}{l}\text { herbal, citrus, sour, brussels sprout, bitter, earthy, } \\
\text { dried hay, strong, spicy }\end{array}$ \\
\hline roasted & $\begin{array}{l}\text { coffee, smokey, chocolate, nutty, roasted } \\
\text { coffee, caramel, cocoa, chocolate }\end{array}$ & strong, coffee, chocolate, nutty, sweet, tasty, vain \\
\hline
\end{tabular}

Generally, roasted coffee was the one with the highest overall acceptability (6.2) which is certainly due to the fact that its characteristics, being the same as regular coffee, were familiar to the panelists and consequently preferred. Regarding byproducts, silverskin beverage was slightly preferred than cascara (5.2 against 4.6).

In terms of qualitative sensorial attributes related to each beverage, roasted coffee exhibited familiar aroma and taste profile described as nutty, chocolate and caramel while green coffee was evaluated with different terms, reminded on herbs, earthy, dried hay and woody. Cascara and silverskin beverage were marked with similar terms, related to fruity, sweet, citrus and roasted nuts aroma and taste (Table 2.).

Moreover, Martinez-Saez et al. (2014) conducted the research on silverskin beverage and reported that only $10 \%$ of respondents would drink it the way it was served in the analysis (that is to say in beverages). Nevertheless, $85 \%$ would consume it combined with another ingredient such as milk, sugar, lemon or honey. Das Neves et al. (2019) demonstrated that the addition of concentration pineapple juice in coffee husk beverage as a supplementary ingredient would lead to a higher acceptance due to an increase in flavour and aroma.

Further research can be directed on preparing the same beverages but with byproducts from Robusta and with different content. As an illustration, Martinez-Saez et al. (2014) also conducted a comparison of silverskin from Arabica and Robusta (with a content of 2.5 and 10 $\mathrm{mg} / \mathrm{mL}$ for each variety) through a similar sensory analysis. They found out that such differences in preparation led in distinct perceptions of the attributes studied. This would be explained by the fact that Arabica would have a fine and more aromatic flavour whereas Robusta would becharacterized by a stronger and less aromatic one.

On top of that, it would be interesting to investigate the consumer opinion on such waste-to-value products. Aschemann-Witzel and Stangherlin (2021) demonstrated that consumer acceptance for food by products relies on three different factors depending on the person, the context and the product and it showed that highlighting consumer needs, environmental and health-related benefits of waste-to-value items wouldimpact on the consumer's context factor and make them more desirable. As a result, coffee byproducts have some potential when it comes to consumer acceptance even though some ways to make them more appealing should be investigated in order to reach an acceptability threshold similar to the one of roasted coffee.

\section{Conclusions}

Successful HPLC and spectrophotometric evaluation of green coffee, commonly consumed roasted coffee and coffee byproducts- cascara andsilverskin was conducted, indicating that green coffee beverage can bea rich source of 5-O-caffeoylquinic acid and its derivatives. Furthermore, cascara beverage showed to be a higher potential source of caffeine than silverskin beverage, with satisfactory antioxidant capacity. Further research can be directed into developing functional cascara and silverskin beverages as valueadded food products, since of certain potential showed by sensory assessment given the satisfactory taste and relatively good overall acceptability.

\section{References}

Alves R.C., Casal S., Oliveira M.B.P.P. (2007) Factors influencing the norharman and harman contents in espresso coffee. Journal of Agriculture and Food Chemistry, 55 (5) 1832-1838.

Alves R.C., Oliveira M.B.P.P., Casal S. (2011) Coffee authenticity. In: Oliveira, M.B.P.P., Mafra, I., Amaral, J.S. (Eds.), Current Topics on Food Authentication. Transworld Research Network, Kerala, India.

Alves R.C., Soares C., Casal S., Fernandes J.O., Oliveira M.B.P.P. (2010) Acrylamide in espresso coffee: influence of species, roast degree and brew length. Food Chemistry, 119 (3) 929-934.

Alves R.C., Rodrigues F., Nunes A. M., Vinha A.F., Oliveira M.B.P.P. (2017) State of the art in coffee processing by-products. U: Galanakis, C.M. (ed): Handbook of Coffee processing By-Products, str. 1-26. Academic Press Book, Cambridge, USA.

AOAC method 930.15 (1990) 'AOAC Moisture in animal feed - AOAC method 930.15. Official methods of analysis of AOAC international, 15. izdanje, AOAC International, Arlington, Virginia.

Aschemann-Witzel J., Stangherlin D.C.I. (2021) Upcycled by-product use in agri-food systems from a consumer perspective: A review of what we know, and what is missing. Technological Forecasting \& Social Change, 168120749.

Ates G, Elmac1 Y (2018) Coffee silverskin as fat replacer in cake formulations and its effect on physical, chemical and sensory attributes of cakes. Lebensmittel- Wissenschaft \& Technologie, 90 519-525.

Ballesteros L.F., Teixeira J.A., Mussatto S.I. (2014) Chemical, functional, and structural properties of spent coffee grounds and coffee silverskin. Food and Bioproccesing Technology, 7 (12) 3493-3503.

Bertolino M., Barbosa-Pereira L., Ghirardello D., Botta C., Rolle L., Guglielmetti A(2019) Coffee silverskin as nutraceutical ingredient in yogurt: Its effect on functional properties and its bioaccessibility. Journal of the Science of Food and Agriculture, 99 4267-4275.

Brand-Williams W., Cuvelier M. E., Berset C. (1995) Use of a free radical method to evaluate antioxidant activity. LWT - Food Science and Technology, 28(1) 25-30. doi: 10.1016/S0023-6438(95)80008-5.

British Coffee Association (2016) British Coffee Association - Find the coffee facts. Available at:https://www.britishcoffeeassociation.org/coffee-inthe-uk/coffee-facts. Accessed:10.06.2021.

Budryn G., Nebesny E., Rachwal- Rosiak D. (2013) Stability of hydroxycinnamic acids and caffeine from green coffee extracts after heating in food 
model systems. European Food Research and Technology, 236 969- 978.

Cubero-Castillo E., Bonilla-Leiva A.R., García-Velasques E. (2017) Coffee berry processing by-Product valorization: Coffee parchment as a potential fiber source to enrich bakery goods abstract. Journal of Food Nutrition and Population Health, 1 1-7.

Das Neves J.V.G., Borges M.V., Silva D., de Melo D.S., Leite, C.X.D.S., Santos, M.R.C. (2019) Total phenolic content and primary antioxidant capacity of aqueous extracts of coffee husk: Chemical evaluation and beverage development. Food Science and Technology, $39348-353$.

Davis A.P., Govaerts R., Bridson D.M., Stoffelen P. (2006) An annotated taxonomic conspectus of the genus Coffea (Rubiaceae). Botanical Journal of the Linnean Society, 152 465-512.

Del Castillo M.D., Fernandez-Gomez B., Martinez-Saez N., Iriondo-DeHond A., Mesa, M.D. (2019) Coffee By-products. U: Coffee: Production, Quality and Chemistry (A Farah, ur.). Royal Society of Chemistry, London, UK, Str. 309-334.

Esquivel P. and Jiménez V. M. (2012) Functional properties of coffee and coffee by-products, Food Research International, 46(2) 488-495. doi: 10.1016/j.foodres.2011.05.028.

Farah, A.; de Paulis, T.; Moreira, D.P.; Trugo, L.C.; Martin, P.R.(2006) Chlorogenic acids and lactones in regular and water-decaffeinated Arabica coffees. Journal of Agricultural and Food Chemistry, 54 374-381.

Ferrão J.E.M. (2009) O Café, A Bebida Negra Dos Sonhos Claros; Chaves Ferreira- Publicações S.A, Lisboa, Portugal.

Gloess A.N., Schönbächler B., Klopprogge B., D`Ambrosio L., Chatelai K., Bongratz A., Strittmatter A., Rast M., Yeretzain C. (2013) Comparison of nine common coffee extraction methods: instrumental and sensory analysis. European Food and Research Technology, 236 60727. doi:10.1007/s00217-013-1917-x.

Heeger A, Kosińska-Cagnazzo A, Cantergiani E, Andlaurer W (2017) Bioactives of coffee cherry pulp and its utilisation for production of Cascara beverage. Food Chemistry, 221 969-975.

Huaman-Castilla N.L., Martínez-Cifuentes M., Conrado C., Pedreschi F., Mariotti-Celis M., Pérez-Correa J.R. (2019) The Impact of Temperature and Ethanol Concentration on the Global Recovery of Specific Polyphenols in an Integrated HPLE/RP Process on Carménère Pomace Extracts.Molecules, 243145.

Hudeckova H., Neureiter M., Obruca S., Frühauf S., Marova I. (2018) Biotechnological conversion of spent coffee grounds into lactic acid. Letters in Applied Microbiology, 66 306- 312.

Iriondo-DeHond A, Aparicio García N, Fernandez-Gomez B, Guisantes-Batan E, Velázquez Escobar F, Blanch GP, San Andres MI, SanchezFortun S, del Castillo MD (2019) Validation of coffee by-products as novel food ingredients. Innovative Food Science and Emerging Technologies, 51 194- 204.

Król1 K., Gantner M., Tatarak A., Hallmann E. (2020) The content of polyphenols incoffee beans asroasting, origin and storage effect. European Food Research and Technology, 246 33-39.

Manasa V. (2021) Utilization of coffee pulp waste for rapid recovery of pectin and polyphenols for sustainable material recycle, Waste Management, 10.

Mareček V., Mikyška A., Hampel D., Čejka P., Neuwirthová J., Malachová A., Cerkal R. (2017) ABTS and DPPH methods as a tool for studying antioxidant capacity of spring barley and malt. Journal of Cereal Science, 73, 40-45.

Martinez-Saez N, Ullate M, Martin-Cabrejas M.A (2014) A novel antioxidant beverage for body weight control based on coffee silverskin. Food Chemistry, 150 227-234. DOI: 10.1016/j.foodchem.2013.10.100.

Mesías M., Navarro M., Martínez-Saez N., Ullate M., del Castillo M.D., Morales F.J. (2014) Antiglycative and carbonyl trapping properties of the water soluble fraction of coffee silverskin. Food Research International, 62 1120- 1126.

Murthy P., Naidu M.M. (2012) Recovery of phenolic antioxidants and functional compounds from coffee industry by-products. Food and Process Technology, 5 897-903.

Mussatto S.I, Machado E.M.S., Martins S., Teixeira J.A. (2011) Production, composition, and application of coffee and its industrial residues. Foodand Bioprocess Technology, 4 661- 672.

Nguyen Phuong D.D., Truc Quynh H.T., Hong Anh L.T. (2019) Optimization of conditions of extraction process from coffee cherry pulp (Cascara) and application to drinking water product with antioxidant activity. Vietnam Journal of Science and Technology, 57 26-32.

Poole R., Kennedy O.J. , Roderick P., Fallowfield J.A., Hayes P.C., Parkes J. (2017) Coffee consumption and health: umbrella review of meta-analyses of multiple health outcomes. BMJ, 359.doi:10.1136/bmj.j5024 Google Scholar.

Pua A., Choo W.X.D., Goh R.M.V., Liu S.Q.,Cornuz M., Ee K.-H., Sun J., Lassabliere B., Yu B. (2021) A systematic study of key odourants, non- volatile compounds, and antioxidant capacity of cascara (dried Coffea arabica pulp), Lebensmittel-Wissenschaft und Technologie, 138 110630. doi:10.1016/j.1wt.2020.110630.

Riberio H.M., Allegro M., Marto J., Pedras B., Oliveira N.G., Paiva A., Barreiros S., Goncalves L.M., Simoes P. (2018) Converting spent coffeegrounds into bioactive extracts with potential skin antiaging and lightening effects. ACS Sustainable Chemistry Enginnering, 6 6289- 6295. Re R., Pellegrini N., Proteggente A., Pannala A., Yang M., \& Rice-Evans C. (1999) Antioxidant activity applying an improved ABTS radical cation decolorisation assay, Free Radical Biology and Medicine, 26 1231-1237.

Singleton V.L., Ross J. (1965) Calorimetry of total phenolic with phosphomolybdic phosphotungstic acid agents. American Journal of Enology and Viticulture, 16 144-158.

Statista (2020) Superfoods - Statistics and Facts. Available at: https://www.statista.com/topics/3250/superfoods/. Accessed: 11.06.2021. Statista (2021) Coffee. Available at: https://www.statista.com/outlook/cmo/hot-drinks/coffee/europe. Accessed: 11.06.2021.

Summa C. A., Calle B., Brohee M., Stadler R.H., Anklama E. (2007) Impact of the roasting degree of coffee on the in vitro radical scavenging capacity and content of acrylamide. LWT- Food Science and Technology, 40(10) 1849-1854 doi: 10.1016/j. 1wt.2006.11.016. Yoo D.E., Jeong K.M., Han S.Y., Kim E.M., Jin Y., Lee J. (2018) Deep eutectic solvent-based valorization of spent coffee grounds. Food Chemistry, 255 357-364. 